\title{
Global Positioning System for Object Tracking
}

\author{
Abha Damani \\ Integrate M.Sc. (IT), \\ Uka Tarsadia University, \\ Bardoli, Gujarat.
}

\author{
Hardik Shah \\ Integrate M.Sc. (IT), \\ Uka Tarsadia University, \\ Bardoli, Gujarat. \\ Manish Vala \\ Ass. Professor,
}

Department of Computer Science and Technology,

Uka Tarsadia University,Bardoli, Gujarat

\begin{abstract}
Global Positioning System is globally used for the tracking and navigation purpose. GPS is mainly used in the military, farming, civil, transportation and commercial users around the world. Here in this review paper, we describe how GPS Tracking System works and where it is useful in real world environment. We compare different algorithms like Localization algorithm, kalman filter algorithm and methodologies like GPS, GPRS, GSM, GIS, GSM and RFID. We have identified some problems of GPS.
\end{abstract}

\section{General Term:}

Kalman Algorithm, Localization Improvement Algorithm

Keywords:

GPS, GSM, RFID.

\section{INTRODUCTION}

Location awareness (Object Tracking) and navigation are becoming one of the most important requirements of the people [1]. Personal navigation and location based services are provided by the GPS. The GPS project was developed in 1973 to overcome the limitations of previous navigation systems [2], integrating ideas from several predecessors, including a number of classified engineering design studies from the 1960s. GPS was created and realized by the U.S. Department of Defense (DOD) and was originally run with 24 satellites [1].

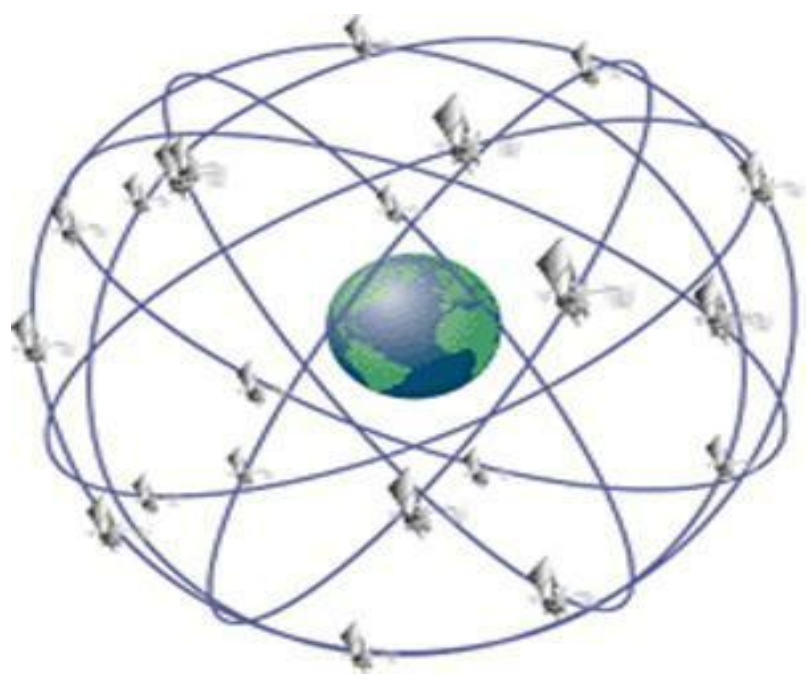

Figure 1 In GPS 24 satellites around the Earth [3]

The Global Positioning System (GPS) technology is a satellite-based navigation system that has been use since forty years. It was designed for military purposes. It is being used for geology, navigation, farming, precision mapping, surveying, and additional applications are on stand growing [1].

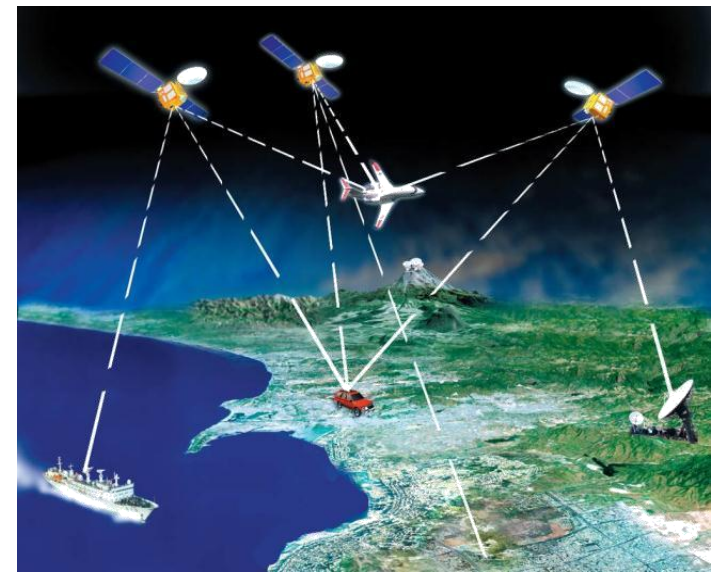

Figure 2 Object Track by 3 GPS satellites [4]

GPS is a Global Navigation Satellite System (GNSS).

GNSS is a system for location or position determination so it's called as a geo positioning. Using a special receiver, a geo position in space and time can be calculated based on the reception of satellite signals [6].

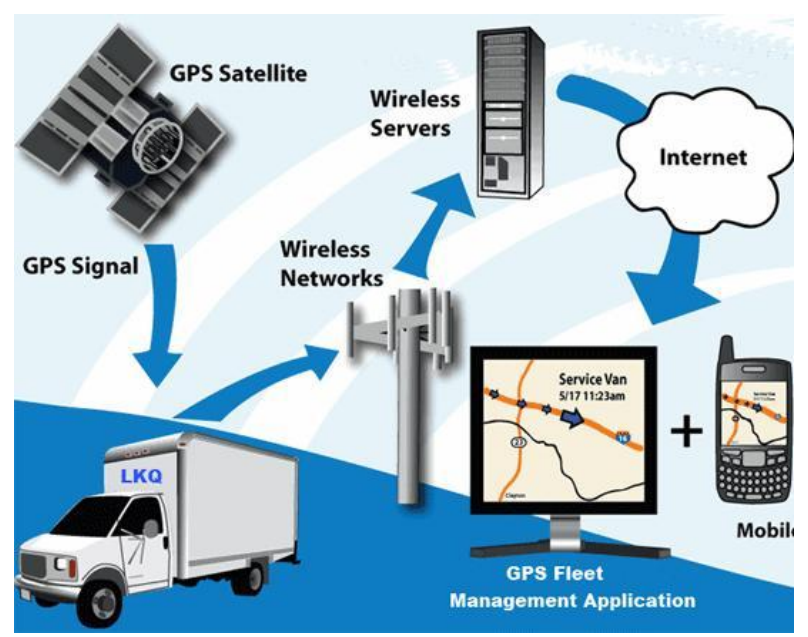

Figure 3 Object Tracking System using GPS \& GSM [5]

Now a days, also smart phone provide the built in facilities for the navigation and tracking. So there is reduction in the size of the GPS receivers and the integration of GPS with mobile phones. 
Paper is organized as below. In section 2 we have done literature of different papers describing working of GPS and algorithms used in it. Section 3 shows the methods and algorithm for the GPS and finally in section 4 we give conclusion of the Literature review.

\section{RELATED WORK}

\subsection{Literature Review}

In [7], GPS and GSM based model are used for routing and tracking of mobile vehicles in a large area outdoor environment. In this model it has a GPS Unit, that continuously moves with the car and will calculate the coordinates of each position and communicate to GSM device which is installed in both Transmitter and receiver section.

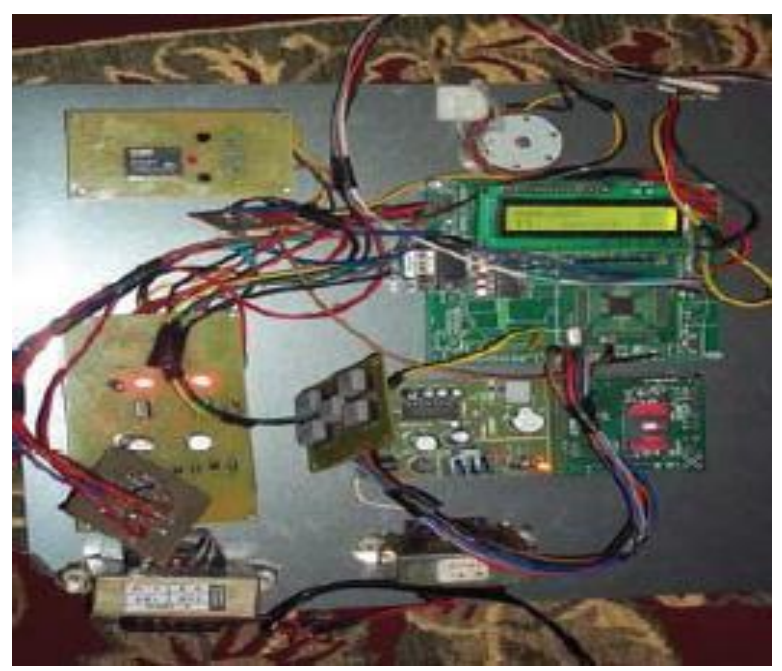

Figure 4 Transmitter Section inbuilt in the vehicle [7]

The device will collect position and display on Google Earth and so the current position of the car can be known. The advantage of this model is, we can easily identify the theft vehicle and also improve routing and tracking in transportation, they use hardware which has arm processor. And Limitation is that when the movement occurs at that time we will get the location, so data may not come by the GPS Unit.

GPS based low-cost vehicle tracking and monitoring system is proposed in [8], it includes a transmitting of retrieve location and vehicle status information and then send it to the other stationary module; the second part is the receiving module which collects the transmitted information by SMS and process it to a compatible format to Google Earth to view the location and vehicle status online.

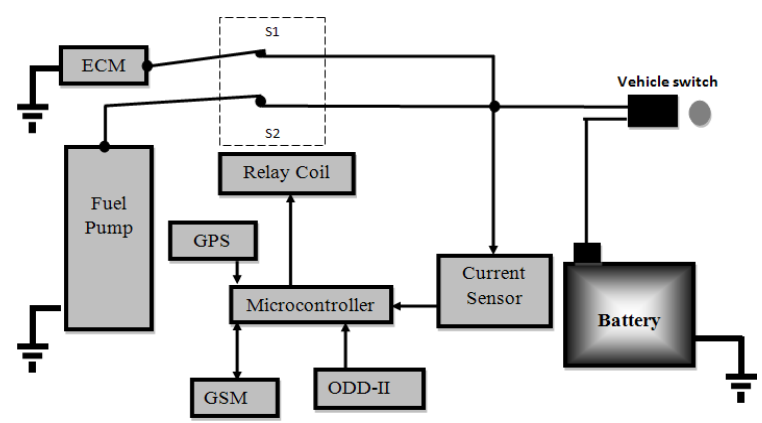

Figure 5. Structure of Anti-theft system [8]
They use kalman algorithm to recognize the actual location of object. While vehicle is running, SMS is passed to the authenticated person. Model has tracking unit, which track the movement of vehicle and after certain period of time the data is send to the authenticate person.

The advantages of this system are that it is inexpensive and light weight, and disadvantage is that if the authenticated person is unavailable then the problem may arise.

The uses of GPS technology incorporated with road mapping are in [9]. The GPS data receiver application and traffic analysis system was developed which collects the GPS traffic data and provides the ability for monitoring and analyzing traffic scenarios on the roads.

Advantages of this system is that ,all these aspects can be analyzed both in real-time and historically based on the fact that historical data is captured and stored for future use and problem is that it requires large size of database to store all the data.

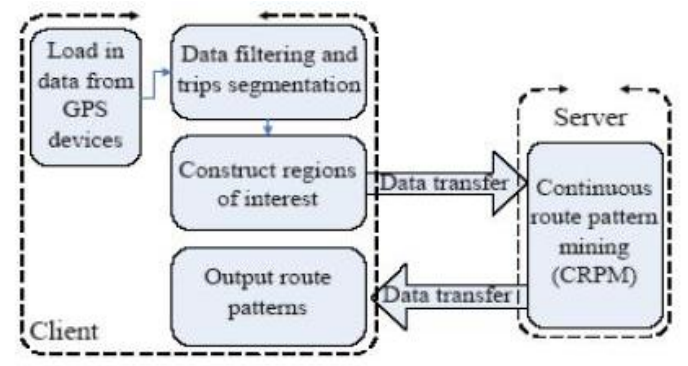

Some traffic management measures use sophisticated systems.

For Remote control of the vehicle tracking location through GPS tracking \& detection of object to avoid collision is available in [10].AVL is an advanced method used to track and monitor any remote vehicle equipped through GPS satellite. AVL is a combination of GPS and GIS that provides actual geographical real time position of each vehicle.

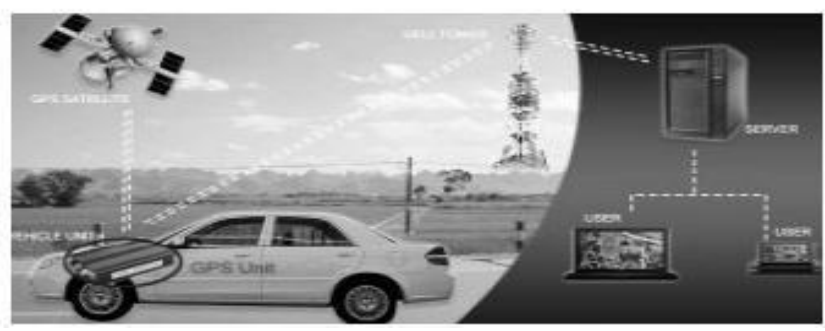

Figure 7 AVL Tracking [10].

Main Benefits of this AVL is that it contains execution of Startup routine, Logs of Tracking Server and Pointing out current location of vehicle so we can easily track and get detail of the vehicle. But in case of long distance between vehicles RFID is not applicable.

Location awareness and navigation is becoming one of the most important features in mobile phones and smartphones. Its description is in [11]. Mobile phones and smartphones usually have relatively low cost GPS chips.

It proposes the LBS in GPS interfering spots by integrating information of multiple sensors such as gyroscope and compass in smartphones. Localization improvement algorithm implemented in smartphone and test in campus. 
This algorithm gives GPS positioning error in a smartphone when the user is nearby high rise building.

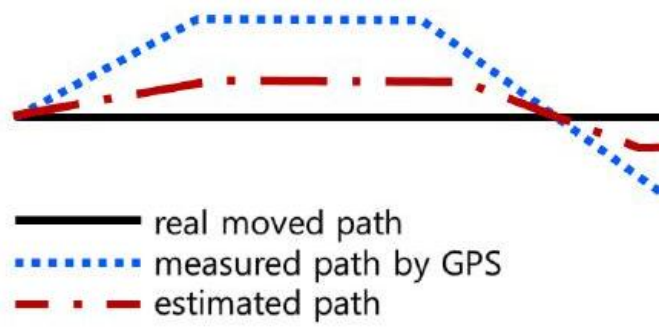

Figure 6 Conceptual Models [9].

They conclude that to solve the traffic problem in the cities, following concept can be used:

1. Any Nation intending to adopt the model must put in place a policy and/or law prompting all vehicle owners to fit their vehicles with GPS trackers.

2. GPS traffic management is considered as a priority traffic management.

The experimental results in the GPS interfering spot. The GPS location information deviates from the real path moved. On the other hand, the adjusted location information through the proposed algorithm can trace the movement path more accurately.

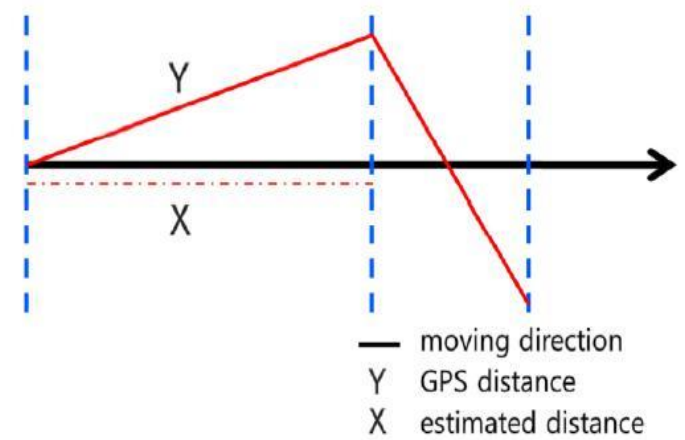

Figure 9. Result of Localization Algorithm by Trigrometric Function [11].

The proposed algorithm has better performance than the GPS location information in GPS interfering spots and maintains reasonable performance in open spaces where the GPS receiver is accurate.

Combination of GPS and GSM is used in [12] .In this system CMOS-8bit Microcontroller is used and it is based on RISC architecture. It uses the MAX232 for serial communication for GPS, GSM and Microcontroller, 16x2 LCD is used to display the location value.

The monitoring unit consists of a GSM mobile and a Web Application. The GSM mobile acquires the position of the vehicle (longitude and latitude) and then by typing those co-ordinates in web application owner of vehicle can get the exact location of the vehicle.

This has limitation with GPS device and a two way communication process is achieved using a GSM modem. GSM modem, provided with a SIM card uses the same communication process as we are using in regular phone.
The system is not limited to find the location of the target but also calculates the distance travelled b/w two stations.

Advantages of this Model is that it is user friendly, easily installable, easily accessible and can be used for various purposes. After installation system will locate the target by the use of a Web application (HTML based application) in Google map. The system allows to track the target anytime and anywhere in any weather conditions.

Also Existing technology like Automatic navigation system, GPSylon and open GTS. In this paper, tracking system consist of components like GPS satellite, car or person with compatible Device, GSM service provider, tracking server and Client PC which are defined in [21].

GPS satellite sends the GPS data to the device which store the temporal stores data in the case of the car used the AVL (Advanced Vehicle Locator). Advantages of the system are that it has SIM card, So we can easily Identify the Object. SIM card which is used to communicate with the local GSM network thus the device uses GPS as well as GSM network.

Problem is that require high level data storage for database. We can use the data whenever we want it for getting reports, for live tracking, for preparing Keyhole Markup Language (KML) and other purposes. KML is a file format used to display the geographical data of the earth in browser, such as Google Earth, Google Maps, and Google Maps for mobile.

All this paper has some methods for GPS data store, retrieve and transmit via some methods. All this methods are described in the next session.

\section{METHODS AND ALGORITHMS 3.1. Methods}

During literature review studies the basic method for the Object Tracking on the Global Positioning System; all this methodologies are describing bellow:

\subsubsection{Object Tracking using GPS}

If want to track any object using GPS then we can track through satellite and GPS Unit. Satellite is used for receive and transmit the data from GPS Unit. It is used at client side for connecting with satellite. It displays the Longitude and Latitude which is received from the satellite. We can also attach the external Hardware for more functionality of tracking like sending all the details of object, sending SMS to authenticated person.

\subsubsection{Object Tracking using GPS and GSM}

If want to track any object using GPS and GSM then it has combination of GPS network and GSM network. From the GPS network whatever data will be received by GPS Unit it will be transmitted to server via GSM network. After processing the data, it is transferred to another application (like on website or on phone). It also used in AVL (Automatic Vehicle Location) and GIS (Geographical Information System).

\subsubsection{Object Tracking using RFID}

If want to track any object using RFID then it has combination of GPS network and GSM network. From the 
GPS network whatever the data will be received by GPS Unit it will be transmitted to server via GSM network. After processing the data, it is transferred to RFID receivers which are communicated with the other RFID receivers to send it in the result of RFID on GSM network.

\subsection{Method Comparison}

All these methods have some features and limitations which are define in the following table:

Table 1: Method Comparison of GPS Tracking

\begin{tabular}{|c|c|c|c|c|}
\hline $\begin{array}{l}\text { Method } \\
\text { Name }\end{array}$ & Method Component & Advantages & Disadvantages & $\begin{array}{l}\text { Referen } \\
\text { ce }\end{array}$ \\
\hline GPS & $\begin{array}{l}\text { Satellite, } \\
\text { GPS Unit, } \\
\text { Micro controller } \\
\text { (data processing in } \\
\text { standalone application) }\end{array}$ & $\begin{array}{l}\text { 1. Easy of navigation and } \\
\text { localization. } \\
\text { 2. Search based on area } \\
\text { 3. Weather information is } \\
\text { determine } \\
\text { 4. World Wide availability }\end{array}$ & $\begin{array}{l}\text { 1. Fast decrease batter life of } \\
\text { any hardware. } \\
\text { 2. Obstracles deflect the signal } \\
\text { 3. Signal multipath, fading, } \\
\text { diffraction is occurring. }\end{array}$ & [7] \\
\hline $\begin{array}{l}\text { GPS and } \\
\text { GSM }\end{array}$ & $\begin{array}{l}\text { Satellite, } \\
\text { GPS Unit, } \\
\text { Server, } \\
\text { GMS Unit, } \\
\text { Micro controller }\end{array}$ & $\begin{array}{l}\text { 1. Ability to use repeaters. } \\
\text { 2. Its provide the stable network. } \\
\text { 3. User or Subscriber can switch } \\
\text { over network. } \\
\text { 4. Roaming type issues is not } \\
\text { available. }\end{array}$ & $\begin{array}{l}\text { 1. Fixed maximum cell } \\
\text { coverage area. } \\
\text { 2. Nature transmission } \\
\text { interface is occur. } \\
\text { 3.high complexity of the } \\
\text { system }\end{array}$ & [10] \\
\hline RFID & $\begin{array}{l}\text { RFID Transceiver, } \\
\text {,GPS Unit, } \\
\text { GSM Unit, Satellite, } \\
\text { Server, } \\
\text { Antenna, } \\
\text { Transponder, } \\
\text { RFID Tag }\end{array}$ & $\begin{array}{l}\text { 1. Not require to line of sight } \\
\text { should be clear. } \\
\text { 2. Easily perform the data } \\
\text { updation. } \\
\text { 3. Human interaction is not } \\
\text { requiring. } \\
\text { 4. RFID tags is easily install in } \\
\text { any place } \\
\text { 5. Its size and weight is small } \\
\text { then easily carry out to any where }\end{array}$ & $\begin{array}{l}\text { 1. Only } 8 \text { frequency band is } \\
\text { available. } \\
\text { 2. It's have no any standard. } \\
\text { 3. Difficult for RFID reader } \\
\text { to read data from the RFID } \\
\text { tags which is in the liquid and } \\
\text { metal }\end{array}$ & [10] \\
\hline
\end{tabular}




\subsection{Algorithms}

During literature review studies the basic algorithm for the Object Tracking on the Global Positioning System; this entire algorithm is described as bellow:

\subsubsection{Localization Improvement Algorithm}

This localization improvement algorithm in GPS interfering spots by integrating information of multiple sensors such as gyroscope and compass in smart phones. The proposed algorithm is implemented in a smart phone [12]. There are 3 steps to implement this algorithm:

1. Structure of Algorithm:- The proposed algorithm consists of three steps:

1. Finding the correct direction of movement.

2. Obtaining the distance moved, and

3. Integrating the prior results and GPS location information.

To obtain the direction of movement, get the heading from the built-in compass in the smart phone. However, the compass is highly dependent on the ambient magnetic field so it has lower accuracy.

To obtain more accurate values of the user's heading, we stabilize the heading value of the compass by recurrence processing of the data. After obtaining the direction of the movement of the user, the distance moved is calculated by the summation of the distances of each coordinate from the GPS location information.

2. Recurrence Processing Function of Compass Heading

$\mathrm{x}_{0}=\mathrm{a}_{0}$

$\mathrm{x}_{1}=\left(\mathrm{x}_{0}+\mathrm{a}_{1}\right) / 2$

$\mathrm{x}_{\mathrm{n}}=\left(\mathrm{x}_{\mathrm{n}-1}+\mathrm{a}_{\mathrm{n}}\right) /(\mathrm{n}+1)$

\section{$\mathrm{x}_{\mathrm{i}}$ : accumulated heading value}

\section{$\mathrm{a}_{\mathrm{i}}$ : a new compass value}

Figure 10. First Equation of the Recursive function [11]

The measurements of the compass in Smartphone are highly dependent on the ambient magnetic field so its accuracy is low. For this reason, here stabilize the measurements of the compass by averaging.

$\mathrm{x}_{0}=\mathrm{a}_{0}$

$\mathrm{x}_{1}=\left(\mathrm{x}_{0}+\mathrm{d}_{1}+\mathrm{a}_{1}\right) / 2$

$\mathrm{x}_{\mathrm{n}}=\left(\mathrm{x}_{\mathrm{n}-1}+\mathrm{d}_{\mathrm{n}}+\mathrm{a}_{\mathrm{n}}\right) /(\mathrm{n}+1)$

$\mathrm{x}_{\mathrm{i}}$ : accumulated heading value

$\mathrm{a}_{\mathrm{i}}$ : a new compass value

$\mathrm{d}_{\mathrm{i}}$ : difference of heading

Figure 11. Second Equation of the Recursive function [11].
The heading value of the compass can be stabilized. But the real heading of a user varies continuously as the user moves. To adjust this value, here apply the difference between the previous heading and current heading and process it recursively.

\subsubsection{Kalman Filter Algorithms}

Kalman filtering, also known as linear quadratic estimation (LQE).Kalman filter is implemented to reduce GPS errors and thus it increases the accuracy of the localization system. The algorithm works in two-step process.

1. In the prediction step, the Kalman filter produces estimates of the current state variables, along with their uncertainties.

2. Once the outcome of the next measurement (necessarily corrupted with some amount of error, including random noise) is observed, these estimates are updated using a weighted average, with more weight being given to estimates with higher certainty.

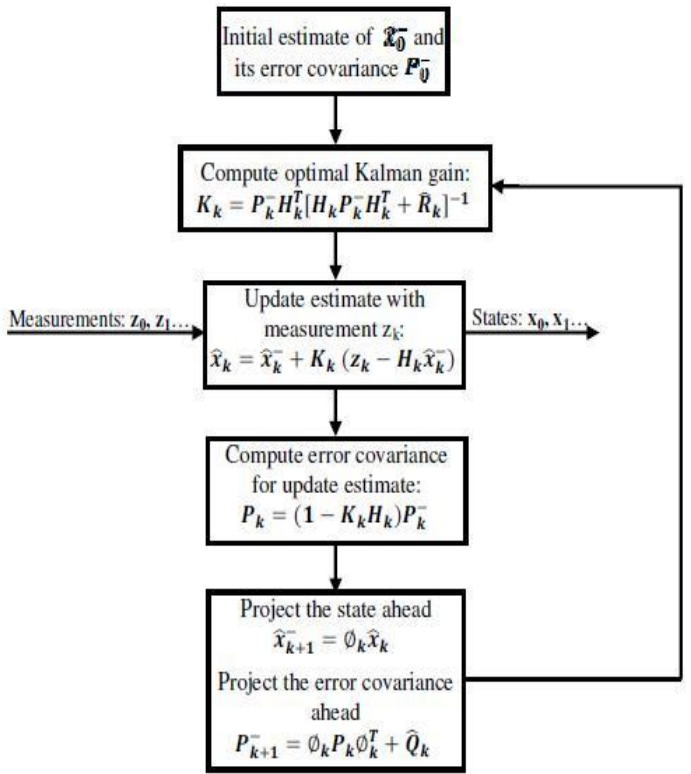

Figure 12 Kalman Filter Procedure for estimating of GPS receiver coordinates [23].

The algorithm's recursive nature, it can run in real time using only the present input measurements and the previously calculated state and its uncertainty matrix; no additional past information is required.

\section{CONCLUSION}

From all this literature review we have get some problem like Signal Multipath, Receiver and Orbital Clock error, Environmental problem like Ionospheres delay,trophoesfer delay , delay because of the distance and delay in time, low accuracy in result.

So, we conclude that we want to solve the increase in accuracy of actual location of object and resulting Location. 


\section{REFERENCES}

[1] http://en.wikipedia.org/wiki/Global_Positioning_Sy stem. Date: 10/12/2014

[2] National Research Council (U.S.). Committee on the Future of the Global Positioning System; National Academy of Public Administration (1995). The global positioning system: a shared national asset: recommendations for technical improvements and enhancements. National Academies Press. p. 16. ISBN 0- 309-05283-1. Retrieved August 16, 2013., Chapter 1, p. 16, Date : 10/12/2014

[3] http://goo.gl/McV0AH . Date: 10/12/2014

[4] http://goo.gl/4XrbtQ . Date: 10/12/2014

[5] http://goo.gl/0KVFPL . Date: 10/12/2014

[6] http://en.wikipedia.org/wiki/GNSS_applications Date: $10 / 12 / 2014$

[7] Sathe Pooja," Vehicle Tracking System Using GPS", International Journal of Science and Research (IJSR), India Online ISSN: 2319-7064, 2013.

[8] Montaser N. Ramadan, Mohammad A. Al-Khedher, Sharaf A. Al-Kheder," Intelligent Anti-Theft and Tracking System for Automobiles", International Journal of Machine Learning and Computing, Vol. 2, No. 1, February 2012.

[9] Obuhuma, J. I., Moturi, C. A., " Use of GPS With Road Mapping For Traffic Analysis", International Journal of Scientific and Technology Research ,Volume 1,Issue 10,ISSN 2277-8616,10 November 2012.

[10] Devyani Bajaj, Neelesh Gupta," GPS Based Automatic Vehicle Tracking Using RFID", International Journal of Engineering and Innovative Technology (IJEIT) Volume 1, Issue 1, January 2012.

[11] Soyoung Hwang and Donghui Yu," GPS Localization Improvement of Smartphones Using Built-in Sensors", International Journal of Smart Home Vol. 6, No. 3, July, 2012.

[12] Pankaj Verma, J.S Bhatia," Design and Development of GPS_GSM Based Tracking System with Google Map Based Monitoring “, International JouRrnal of Computer Science, Engineering and Applications (IJCSEA) Vol.3, No.3, June 2013.

[13] [13].Akin ode J. L1, Alamode A. J2 and Ojuawo O. O3. Nigeria, "Improving National Security using GPS Trackinsystem Technology". Proceedings of the $1^{\text {st }}$
International Technology, Education and Environment Conference(c) African Society for Scientific Research (ASSR).

[14] [14]. Ambade Shruti Dinkar, S. A. Sackh, "Design and implementation of Vehicle tracking system using GPS", Journal of Information Engineering and Applications, Vol 1, No. 3, 2011.

[15] [15].Allan Brimicombe, Chao Li, "Location Based Services and Geo-information Engineering", Willey BlackWell - A John Willey \& Sons Ltd. Publications, First Impression 2009.

[16] Moein Mohammadi, Ehasan Molaei, Ali Naserasadi, "A Survey on Location Based Services and Positioning Techniques", International Journal of Computer Applications, volume 24-No 5, June 2011.

[17] Albert Alexe, R. Ezhilarasie, "Cloud Computing Based Vehicle Tracking Information systems" , IJCST Vol 2, Issue 1, March 2011.

[18] Barkuus, Louise, "Location Based Services for Mobile Telephony". Intel Corporation, 2003.

[19] Wang, Shu, Jungwon Min and Byung K. Yi, "Location based services for mobiles: Technology and Standards". IEEE international conference on ommunication (ICC) Beijing, China; 2008.

[20] Siegrist, D., Clivaz, C., Hunziker, M. \& Iten, S. (eds.) (2006). "Exploring the Nature of Management", Proceedings of the Third International Conference on Monitoring and Management of Visitor Flows in Recreational and Protected Areas. University of Applied Sciences Rapperswil, Switzerland, 13-17 September 2006. Rapperswil.

[21] Sameer Darekar, Atul Chikane, Rutujit Diwate, Amol Deshmukh, Prof. Archana Shinde ," Tracking System using GPS and GSM: Practical Approach", International Journal of Scientific \& Engineering Research Volume 3, ISSN 2229-5518, Issue 5, May2012.

[22] Deepak Mishra1, Apurv Vasal2, Puneet Tandon,” A Novel and Cost Effective Approach to Public Vehicle Tracking System", International Journal of UbiComp (IJU), Vol.3, No.1, January 2012.

[23] Mohammad A. Al-Khedher," Hybrid GPS-GSM Localization of Automobile Tracking System", International Journal of Computer Science \& Information Technology (IJCSIT) Vol 3, No 6, Dec 2011. 